\title{
CADASTRO, DIAGNÓSTICO E RECUPERAÇÃO DAS ÁREAS VERDES PÚBLICAS URBANAS DE CRICIÚMA/SC
}

\section{REGISTRATION, DIAGNOSIS AND RESTORATION OF PUBLIC URBAN GREEN SPACES IN CRICIÚMA/SC}

\author{
Renan Yamashita Ferreira ${ }^{1}$
}

\begin{abstract}
RESUMO
As áreas verdes do município são áreas destinadas a manter vegetação, sendo importantes para a qualidade ambiental da cidade. Este artigo relata o trabalho de levantamento, cadastro, diagnóstico e recuperação das áreas verdes públicas urbanas de Criciúma/SC criadas nos processos de loteamentos. Foram consultados os mapas dos processos de loteamentos aprovados, as áreas verdes foram demarcadas em mapas e suas informações cadastradas em uma planilha. Posteriormente foram realizadas vistorias nas áreas, sendo elaborado um diagnóstico das mesmas com a descrição da vegetação, dos fatores de degradação e as ações necessárias para melhoria. Em algumas áreas foram realizadas ações como plantio de árvores, aporte de matéria orgânica, cercamento e remoção de espécies invasoras e resíduos, através das obrigações de compensação ambiental. Observamos a importância e recomendamos envolver a comunidade local, que pode auxiliar a recuperação da área ou causar degradações quando ignorada. $\mathrm{O}$ problema das invasões deve ser coibida com pronta fiscalização, sendo mais eficiente com a vigilância da comunidade.
\end{abstract}

PALAVRAS-CHAVE: Áreas Verdes Urbanas, Arborização Urbana, Recuperação Ambiental.

\begin{abstract}
The green spaces of the city are spaces destined to maintain vegetation, being important for the environmental quality of the city. This article reports the work of survey, registration, diagnosis and restoration of the urban public green spaces of Criciúma/SC created in the urban allotment processes. The maps of the approved allotments processes were consulted, the green spaces were demarcated on maps and all the information were registered in a spreadsheet. Later, these areas were visited, elaborating a diagnosis with the description of the vegetation, the degradation factors and the necessary actions for improvement. In some areas, it was carried actions like planting trees, input of organic matter, fencing and removal of invasive species and waste, through environmental compensation obligations. We note the importance and recommend engaging the local community, who can assist the recovery of the area or cause degradation when ignored. The problem of intrusions should be restrained with ready inspection, which is more efficient with the surveillance of the community.
\end{abstract}

KEYWORDS: Urban Green Spaces, Urban Forestry, Environmental Restoration.

\footnotetext{
${ }^{1}$ Analista em Infraestrutura de Transportes - Ambiental. Departamento Nacional de Infraestrutura de Transportes. SAN Quadra 03, Bloco A - Asa Norte - Via L2 Norte - Brasília/DF, Brasil. CEP: 70040902. E-mail: renanyferreira@gmail.com
} 


\section{INTRODUÇÃO}

Este artigo tem como objetivo relatar o trabalho de levantamento, cadastro, diagnóstico e recuperação das áreas verdes do município de Criciúma/SC, criadas nos processos de parcelamento do solo. O trabalho foi desenvolvido pelo autor enquanto trabalhava na Fundação de Meio Ambiente de Criciúma (FAMCRI). O objetivo é servir como guia e inspiração para que outros municípios realizem o mesmo trabalho, valorizando suas áreas públicas destinadas a manter vegetação.

A arborização dos ambientes urbanos traz inúmeros benefícios ambientais à cidade: a manutenção do equilíbrio climático, o favorecimento da infiltração da água no solo, prevenindo a erosão e as enxurradas. Também ameniza a poluição sonora e purifica o ar pela fixação das poeiras, materiais residuais e reciclagem de gases tóxicos. Além de todos estes benefícios ambientais diretos, há também os benefícios estéticos e psicológicos, que refletem no bem-estar das pessoas (LIMA NETO, 2011).

Além dos benefícios proporcionados pelas árvores em geral, a presença de florestas e remanescentes de vegetação nativa no ambiente urbano tem importante papel ecológico, como a preservação de habitats para a biodiversidade e a função de trampolins ecológicos auxiliando os fluxos gênicos através da paisagem (METZGER, 2003). Estes remanescentes apresentam também benefícios diretos aos humanos, como a possibilidade de realizar trilhas nos ambientes naturais e ter contato direto com a natureza (NEDER, 2013).

Nas grandes cidades impera a especulação imobiliária e a alta valorização econômica dos espaços. Neste contexto, os proprietários de terra se vêem na necessidade de auferir vantagem econômica de seus terrenos. Nestas áreas particulares, qualquer obrigação de preservar, mesmo que determinada por lei, gera conflitos entre o interesse particular e a legislação e preservação ambiental.

Desta maneira, as áreas de domínio público destinadas à preservação apresentam importância especial na qualidade ambiental da cidade, pois nelas o poder público pode empregar esforços de conservação e recuperação diretamente, sem entrar em conflito com proprietários. Dentre estas áreas, destacam-se as Áreas de Preservação Permanentes e as Áreas Verdes, estas últimas criadas no processo de parcelamento do solo. 
Conforme o Guia do Parcelamento do Solo Urbano do Ministério Público (MP/SC) de Santa Catarina (2010), “35\% da área a ser loteada deve ser destinada às áreas de uso comum, que são: área institucional, área de arruamento e área verde.” O percentual a ser destinado especificamente para área verde é determinado por cada município. Em Criciúma as áreas verdes devem possuir 10\% da área útil a ser loteada.

É entendimento também do MP/SC que, quando da inserção de área rural em zona urbana ou de expansão urbana, a reserva legal da propriedade deverá alterar seu instituto para área verde urbana, mantendo-se inalteradas suas características ambientais, salvo pequenas alterações de destinação e aproveitamento admitidas para o segundo instituto (SOUTO, 2010).

Segundo Abreu (2004), em Santa Catarina, aos municípios que não possuem legislação específica acerca da questão e que seus Planos Diretores nada informarem, aconselha-se a tomar como base, por analogia, o artigo 11 da Resolução Conjunta IBAMA/FATMA 001/95, que determina a fixação, em espaços urbanos onde haja ocorrência de mata atlântica, de $8 \mathrm{~m}^{2}$ de área verde por habitante. No caso específico, a existência ou não de mata atlântica torna-se sem efeito.

No entanto, apesar da obrigatoriedade da instituição destas áreas verdes nos novos loteamentos, não consta na legislação como estas áreas devem ser manejadas e utilizadas, de modo a minimizar os impactos negativos causados pela vizinhança urbana. Afirmando isto, Laudares et al. (2013) defende a criação de normas ou decretos para suprimir ações anti-conservacionistas proporcionadas pelas brechas da Lei.

Conforme Silva (1995), as áreas verdes ideais "são caracterizadas pela existência de vegetação contínua, amplamente livre de edificações, ainda que recortadas de caminhos, vielas, brinquedos infantis e outros meios de passeio e divertimento leves, quando tais áreas se destinam a uso público".

\section{MATERIAL E MÉTODOS}

\section{LEVANTAMENTO E CADASTRO DAS ÁREAS VERDES}

O trabalho iniciou em outubro de 2012, com o objetivo de saber quais eram e onde e como estavam as áreas verdes do município, pois nenhum setor da prefeitura possuía um cadastro destas áreas. 
Desta maneira, iniciou-se a pesquisa na fonte: foram analisados todos os processos de loteamento arquivados no Departamento de Planejamento Físico e Territorial (DPFT), observando a planta dos mesmos e a demarcação da área verde (quando existente, já que alguns projetos mais antigos não reservavam esta área), bem como outras Áreas de Preservação demarcadas.

Também foi oficiado o $1^{\circ}$ Ofício do Registro de Imóveis, para que nos enviassem todas as plantas disponíveis que registraram áreas verdes. Desta maneira, nos foram enviadas diversas plantas antigas e outras informações que ampliaram o nosso cadastro.

Todas as plantas foram fotografadas e as áreas localizadas no mapa do Google Earth, para visualização e localização mais prática. Todas as informações foram reunidas em uma planilha, com o loteamento que criou cada área, ano de criação, bairro, tamanho e mapas correspondentes.

Posteriormente, verificamos no Setor de Cadastro da prefeitura como tais áreas estavam cadastradas pelo município. Nas áreas em perfeita situação constava que o proprietário é o Município de Criciúma e em seu complemento: “Área Verde”. Outras áreas são apenas de propriedade do município (não sendo discriminadas como Áreas Verdes) e outras pertencentes a particulares.

\section{DIAGNÓSTICO DAS ÁREAS VERDES}

O diagnóstico das áreas foi realizado primeiramente por imagens aéreas, através das quais foi possível observar se a área era ocupada por vegetação, com solo exposto, ou ocupada por edificações.

Posteriormente, foram realizadas vistorias de campo nas áreas, nas quais eram registradas informações sobre a vegetação: se haviam árvores isoladas ou mata em estágio inicial ou médio de regeneração, com presença ou dominância de espécies exóticas.

Além disso, eram registrados fatores de degradação, como lixo doméstico ou resíduos da construção civil, esgoto, desmatamento, pastoreio, cerca danificada. Registramos também quaisquer usos que estivessem acontecendo na área, como andarilhos usando como abrigo, vizinhos usando como estacionamento, ou mesmo usos institucionais. Nos casos em que encontramos vizinhos da área com algum interesse, 
registramos no relatório o seu contato para colaboração ou participação em futuros projetos.

Foram estudadas também as possibilidades de recuperação da área, listando algumas preocupações e ações necessárias, bem como outros usos possíveis compatíveis com a realidade local.

Desta maneira, foi elaborado um relatório final, classificando as áreas conforme a sua situação burocrática/legal e física/ambiental, conforme as categorias a seguir:

- Áreas Verdes Reconhecidas e Preservadas: Aquelas identificadas no cadastro do município como áreas verdes, e apresentando dominância de vegetação nativa, geralmente em estágio inicial ou médio de regeneração, em alguns casos com pequenos problemas como indivíduos de espécie exótica ou deposição de lixo. Do ponto de vista conservacionista, são as áreas em situação ideal.

- Áreas Verdes Reconhecidas e Degradadas: Embora cadastradas pelo município como áreas verdes, tais áreas encontravam-se degradadas em situações diversas. Estas são as áreas prioritárias para realizar melhorias, em algumas delas foram realizadas ações de plantio de árvores e restauração. Também seriam possíveis outros possíveis usos compatíveis, conforme será discutido adiante.

- Áreas do Município Preservadas: Áreas preservadas com mata nativa, porém não cadastradas como "áreas verdes" pelo município. Para estas foi proposta simplesmente sua modificação no cadastro.

- Áreas do Município Degradadas: Apesar de definidas como áreas verdes na criação do loteamento, estas áreas não estavam classificadas como tal, e não apresentam cobertura de vegetação nem qualquer uso institucional.

- Áreas do Município em Utilização: Apesar de criadas como áreas verdes e ainda pertencentes ao município, estas áreas hoje apresentam outra utilização de caráter público, como igrejas, creches, escolas, praças, associação de moradores, campo de futebol.

- Áreas Particulares: Estas áreas foram criadas com loteamentos mais antigos, quando o município não as distinguia como "verdes", sendo apenas propriedade municipal. Desta maneira, ao longo do tempo estas áreas foram vendidas ou permutadas, sendo hoje pertencentes a particulares, não sendo possível exigir sua recuperação ou arborização. 
- Áreas Desafetadas Por Lei: Estas áreas foram desafetadas (deixaram de ser áreas verdes) através de Lei Municipal (todas recentes, entre cinco e dez anos atrás). São agora destinadas a outros usos.

\section{RESULTADOS}

O trabalho levantou as áreas verdes criadas por 146 (cento e quarenta e seis) loteamentos. Como alguns loteamentos criaram mais de uma área, e como também foram contabilizadas as Áreas de Preservação Permanente, há no total mais de duzentas áreas. No entanto, cabe lembrar que diversas delas não existem mais, pois foram desafetadas ou vendidas/permutadas com particulares.

Desta maneira, 44 áreas foram listadas como reconhecidas e preservadas, 43 reconhecidas e degradadas, 7 áreas do município preservadas, 11 áreas do município degradadas, 14 áreas do município em utilização, 21 áreas particulares e 6 áreas desafetadas por lei (Figura 1).

Figura 1: Gráfico ilustrando a situação das Áreas Verdes Cadastradas, quanto a sua situação no cadastro municipal e seu status de conservação.

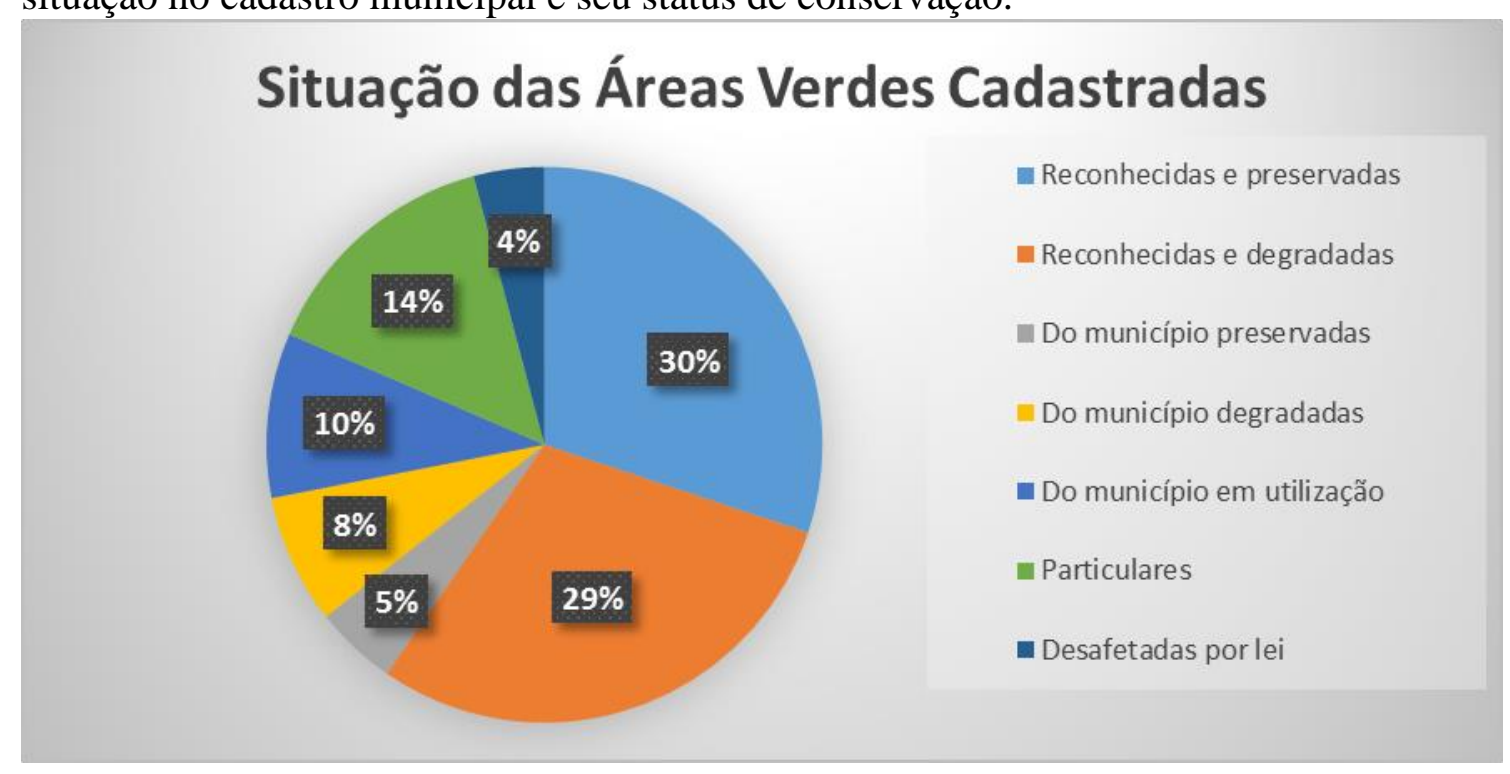

Como há loteamentos com mais de uma área em diferentes situações, a soma destes valores supera os 146 loteamentos levantados.

Conhecidas e cadastradas as áreas, foi possível realizar algumas ações em algumas delas. Todas as ações geraram diversas reflexões e recomendações que devem 
ser levadas em consideração para melhorar a gestão destas áreas, as quais discutiremos a seguir:

\section{DISCUSSÃO}

\section{ESTRATÉGIAS PARA MELHORIA DAS ÁREAS VERDES}

Durante o tempo em que este projeto foi desenvolvido, não foram destinados recursos específicos para melhoria destas áreas. No entanto foi possível promover algumas ações através dos seguintes instrumentos:

Medidas compensatórias para autorização de corte de árvores: Cidadãos ou empresas que obtiveram autorização para o corte de árvores no município se comprometiam, como medida compensatória, a realizar plantio de árvores e/ou outras melhorias nestas áreas, como cercamento, aporte de matéria orgânica, retirada de invasoras ou retirada de resíduos e poluentes.

Este compromisso era firmado através de assinatura de um Termo de Compromisso com a Fundação de Meio Ambiente. Tal instrumento gera uma obrigação formal de cumprir com as compensações, podendo sujeitar o signatário a multas e outras sanções pelo não cumprimento.

As mesmas medidas eram impostas àqueles que foram autuados por infrações ambientais, como maneira de reduzir a multa através de compensação ambiental.

Em todos os casos, era determinada a colocação de uma placa explicativa sobre o plantio e as ações realizadas, como parte do Projeto de Restauração das Áreas Verdes, pois tão importante quanto as ações realizadas é a divulgação e conscientização dos cidadãos.

Apesar de realizadas algumas melhorias, é importante monitorar a área por um longo período, para verificar se as mudas plantadas sobreviveram e cresceram até não necessitarem mais de cuidados, processo que pode levar muitos anos. Com o monitoramento, verifica-se também se não houveram outras interferências negativas ou novos fatores de degradação.

Nos casos em que se deseja a restauração da mata nativa, é necessário observar se está ocorrendo a regeneração natural. Em caso negativo, deve-se identificar os motivos e quais ações são necessárias para restaurar os processos ecológicos.

Em Criciúma e região há um problema especial, que é a degradação pela mineração de carvão. $\mathrm{O}$ processo de beneficiamento do carvão produz um rejeito 
piritoso, que em reação com o ar e a água produz ácido sulfúrico, que acidifica o solo e a água e impede o desenvolvimento de diversas espécies de plantas. Antigamente, este resíduo era disposto indiscriminadamente em áreas naturais.

Embora existam grandes depósitos destes resíduos cadastrados e em recuperação, eles podem ser encontrados espalhados por diversos locais do município, em grandes ou pequenas quantidades, inclusive junto ao material dragado dos rios (operação rotineira devido aos problemas de alagamentos urbanos), que permanece posteriormente nas áreas de preservação.

Há diversas áreas verdes com alguma contaminação de rejeitos piritosos. Nos casos mais graves, há crescimento apenas de eucaliptos e samambaias Pteridium. Em casos mais leves há o desenvolvimento de outras espécies, porém prejudicado. E há casos de apenas algumas manchas onde existem os rejeitos e a vegetação não consegue se desenvolver. Em todos estes casos a restauração exige um projeto mais específico, complexo e dispendioso.

Há diversos gestores que acreditam que o cercamento é uma ação importante e necessária para estas áreas. Apesar de ser importante para conter ou inibir alguns fatores de degradação, como o pastoreio por animais domésticos e a deposição de resíduos, o cercamento somente deve ser adotado quando realmente necessário. Além dos altos custos de construção de uma cerca, ela cria o sentimento de exclusão da comunidade e impede uma simples caminhada pela mata. Também pode impedir alguns usos comunitários interessantes, conforme será discutido a seguir.

\section{O COMPONENTE SOCIAL}

Nas áreas urbanas, é notável que o fator mais importante que determinará o destino das áreas e o sucesso dos projetos é o social. A vizinhança é quem pode fiscalizar ou interferir com mais agilidade em cada área. Da mesma maneira que os vizinhos podem zelar pela área, promover melhorias e auxiliar a fiscalização através de denúncias, é possível que eles destruam a vegetação, as cercas e tornem a área um depósito de lixo.

Inicialmente, é importante a educação. Em todas as áreas onde foram realizadas intervenções, foram colocadas placas explicando que se trata de uma área pertencente a 
todos e destinada a preservar a natureza, indicando as ações proibidas e os meios para realizar denúncias.

Embora não tenha sido possível um trabalho mais intenso diretamente com a comunidade, pudemos observar que isto é muito importante. Desta forma fazemos as seguintes recomendações:

O ideal é que haja um contato direto com os moradores da vizinhança. Em comunidades organizadas isto pode ser realizado mais facilmente, através das associações de moradores e seus representantes. Outra possibilidade é através das escolas locais, os alunos e seus pais. Nas comunidades onde não há união e organização coletiva é justamente onde se apresentam os piores cenários de descaso.

Quando possível, é interessante consultar os moradores sobre qual o uso futuro desejado para aquela área, o que proporcionará maior participação social nos trabalhos e cuidados posteriores. Obviamente, a escolha deve prever a preservação de alguma vegetação (objetivo primário das áreas verdes), mas há muitos usos comunitários permitidos. Porém, caso o desejo necessite de grandes investimentos em infraestrutura talvez se torne inviável, podendo causar frustração na comunidade.

Outra possibilidade interessante para as áreas degradadas, mas que envolve união comunitária e trabalho braçal, é a criação de hortas comunitárias. Embora não preserve necessariamente vegetação nativa, esta utilização representa um benefício ambiental no meio urbano. Além da produção coletiva de alimentos, trata-se de uma interessante ocupação social, afastando os jovens do ócio. Podem ser utilizadas também como ferramenta de educação ambiental, sendo aproveitadas pelas escolas e creches.

Segundo Conti (2009), a agricultura urbana pode ser praticada em qualquer ambiente urbano e periurbano. Entre as vantagens, há a produção de alimentos, a reciclagem de lixo orgânico, utilização racional de espaços ociosos, educação ambiental, segurança alimentar, farmácia caseira, renda, diminuição da pobreza e até mesmo recreação e lazer.

\section{O PROBLEMA DAS INVASÕES}

Trata-se de um problema recorrente em diversos locais no país. Pessoas que não possuem moradia própria (ou com interesses escusos), ao identificarem uma área 
pública ociosa, se apropriam da mesma construindo alguma edificação precária no local, caracterizando a invasão.

Felizmente, conforme a Constituição Federal, as áreas verdes mesmo invadidas não podem ser alvo de usucapião: "Art. 183. Aquele que possuir como sua área urbana de até duzentos e cinquenta metros quadrados, por cinco anos, ininterruptamente e sem oposição, utilizando-a para sua moradia ou de sua família, adquirir-lhe-á o domínio, desde que não seja proprietário de outro imóvel urbano ou rural.

\section{$\S^{\circ}$ : Os imóveis públicos não serão adquiridos por usucapião".}

No entanto, muitas das invasões mais antigas foram regularizadas pelo poder público (algumas das leis desafetando áreas verdes foram para este destino), tornando legítimos proprietários os invasores de antigas áreas verdes.

Há autores como Silva (2003) que afirmam que a desafetação não poderia ser executada, pois "a respectiva área foi doada com a destinação específica de área de lazer e preservação ambiental, como forma, inclusive, de compensação ecológica pela degradação gerada pelo empreendimento". Além disso, "o município não dispõe de forma absoluta dos bens de uso comum do povo ambientalmente relevantes".

Em 2010, o município de Criciúma criou a Lei Complementar $n^{\circ} 84$ de 2010, que institui o Plano Municipal de Contenção de Invasões. Esta lei define os procedimentos e prazos para notificação e desocupação de invasões, bem como a cooperação entre os órgãos. A instituição desta lei fez diminuir bastante os casos de invasão de áreas verdes no município.

Ainda assim, foram encontrados alguns casos recentes de invasão, inclusive em andamento, de cidadãos que estavam cientes de tratar-se de área pública ou área verde. O procedimento administrativo foi oficiar o setor de patrimônio do município, que procede com uma ação na justiça para assegurar a área do município e expulsar o invasor.

Há bairros em que a própria comunidade é unida e protege as áreas públicas das invasões, realizando denúncias com agilidade e às vezes por meio da ação direta dos moradores do bairro unidos, impedindo os invasores de se instalarem nas áreas.

Há muitos casos no país de áreas verdes que não apresentam vegetação nativa nem qualquer uso ou estrutura que as proteja. Nestes casos, os campinhos de futebol 
apresentam uma boa proteção contra invasões em áreas vulneráveis, já que são utilizadas pela comunidade, que irá cuidar estas áreas. Outros usos comunitários, como as hortas já mencionadas, também podem proteger as áreas públicas de invasões.

\section{CONSIDERAÇÕES FINAIS}

O produto deste trabalho é um cadastro geográfico e descritivo de todas as áreas verdes do município, de posse da Fundação do Meio Ambiente de Criciúma. Neste cadastro é possível conferir rapidamente seu local, sua situação, visualizar fotos e quaisquer informações importantes. Trata-se de um cadastro importante para gerir parte do patrimônio do município como também para todos os encarregados de proteger o meio ambiente.

Nestas áreas podem ser desenvolvidos trabalhos técnicos e acadêmicos sobre a recuperação de áreas degradadas em ambientes urbanos. Para viabilizar as operações é possível contar com recursos de compensação ambiental, conforme comentado neste artigo.

A recuperação destas áreas urbanas pode ter objetivos diversos: desde restaurar a vegetação nativa e todos os seus processos ecológicos, ou criar uma área de lazer e utilização dos vizinhos, coberta por árvores e outras plantas. Em todos estes casos haverá uma melhoria ambiental e social para a cidade.

O importante é a valorização destas áreas como patrimônio público, pertencentes a todos os cidadãos e com potencial de melhorar a qualidade de vida de todo o entorno. Este sentimento de apropriação pelas pessoas, especialmente os vizinhos, contribuirá para o zelo, a fiscalização e a melhoria das áreas.

Para isto, é importante que o processo seja participativo. Esta deve ser a principal preocupação dos governantes, que em alguns casos, por praticidade ou defesa de interesses, preferem tomar as decisões sem interferências dos cidadãos.

\section{AGRADECIMENTOS}

Aos colegas da Fundação do Meio Ambiente de Criciúma, em especial aos colegas Rodrigo, Michele e Rafaela, pela seriedade que conduzem seu trabalho e importância que deram a este projeto. 
Aos antigos estagiários Luana, Rafaela, Guilherme, Natália e Samuel, que efetivamente colaboraram na elaboração deste trabalho.

A $9^{a}$ Promotoria de Justiça da Comarca de Criciúma, do Ministério Público de Santa Catarina, através do Promotor Luiz Fernando Góes Ulysséa, que creditou importância a este trabalho, tendo aberto o Inquérito Civil no 06.2013.00002890-5 e solicitado as informações que nos determinou a organizá-las através do relatório.

Futuramente, a todos que de alguma maneira possam dar continuidade a este trabalho, proporcionando melhorias a estas áreas e promover mais qualidade de vida à cidade.

\section{REFERÊNCIAS}

ABREU, A. H.; OliveIRA, R. J. Áreas Verdes e Municípios. Publicado em 04/11/2004. Disponível

em http://documentos.mpsc.mp.br/portal/manager/resourcesDB.aspx? path=614. Acesso em: 05 agosto 2015.

CONTI, E. C. Agricultura Urbana: Desenvolvimento de uma Unidade Agroecológica Comunitária. Trabalho de Conclusão de Curso de Graduação em Agronomia - Universidade Federal de Santa Catarina. Florianópolis, 2009

CRICIÚMA. Lei complementar $n^{\circ} 84$ de 22 de Dezembro de 2010. Institui o Plano Municipal de Contenção de Invasões - PMCI e dá outras providências. Criciúma, 2010. LAUDARES, S. S. A.; BARROS, E. C.; BORGES, L. A. C. Áreas Verdes Urbanas e a Legislação Ambiental. IX Fórum Ambiental da Alta Paulista, v. 9, n. 5, p. 126-134, 2013.

LIMA NETO, E. M. de Aplicação do sistema de informações geográficas para o inventário da arborização de ruas de Curitiba, PR. Dissertação (Mestrado) Universidade Federal do Paraná, Setor de Ciências Agrárias, Programa de PósGraduação em Engenharia Florestal. Curitiba, 2011.

METZGER, J. P. Como restaurar a conectividade de paisagens fragmentadas? In: KAGEYAMA, P. Y.; OLIVEIRA, R. E.; MORAES, L. F. D. de; ENGEL, V.L.; G ANDARA, F. B. (ed.) Restauração ecológica de ecossistemas naturais. São Paulo: Fepaf, 2003. p. $49-76$. 
NEDER, C. P.; SOLINO FILHO, T.; PICOLI, R. L. Ecossistemas Urbanos e a Conservação da Biodiversidade: Benefícios Sociais e Ambientais do Parque de Uso Múltiplo da Asa Sul. In: IV Congresso Brasileiro de Gestão Ambiental. Salvador, 2013.

SANTA CATARINA. Ministério Público. Centro de Apoio Operacional do Meio Ambiente. Guia do parcelamento do solo urbano: perguntas e respostas: consultas e modelos / Coordenado por Luís Eduardo Couto de Oliveira Souto. - Florianópolis: MPSC, 2010.

SILVA, J. A. da Direito urbanístico brasileiro. 2. Ed. Ver. E atual. São Paulo: Malheiros, 1995. 247 p.

SILVA, M. F. da A desafetação de áreas verdes advindas de aprovação de loteamentos perante a tutela ambiental. Jus Navigandi, Teresina, ano 7, n. 113, p. 14, 2003.

SOUTO, L. E. C. de O. A perpetuidade da Reserva Legal em zona urbana e seu aproveitamento como área verde. 2010. Disponível em http://www.mpsc.mp.br/caomeio-ambiente/publicacoes-tecnicas. Acesso em: 10/08/2015. 